\title{
Adaptabilidade e estabilidade de cultivares de trigo em diferentes épocas de semeadura, no Paraná
}

\author{
Raphael Rossi Silva(1), Giovani Benin(2), Giovani Olegário da Silva(3), \\ Volmir Sérgio Marchioro(4), Juliano Luiz de Almeida(5) ${ }^{(5)}$ Gilvani Matei(6) $^{(6)}$
}

\begin{abstract}
(1)Universidade Estadual de Londrina, Centro de Ciências Agrárias, Departamento de Agronomia, Rodovia Celso Garcia Cid, PR 445, Km 380, CEP 866051-990 Londrina, PR. E-mail: raphaelrossi@agronomo.eng.br (2)Universidade Tecnológica Federal do Paraná, Curso de Agronomia, Rodovia PR 469, Km 01, CEP 85501-970 Pato Branco, PR. E-mail: benin@utfpr.edu.br (3)Embrapa Transferência de Tecnologia, Rodovia BR 280, Km 219, Bairro Água Verde, Caixa Postal 317, CEP 89460-000 Canoinhas, SC. E-mail: giovaniolegario@gmail.com ${ }^{(4)}$ Cooperativa Central de Pesquisa Agrícola da Nossa Terra, BR 467, Km 98, CEP 85813-450 Cascavel, PR. E-mail: volmir@coodetec.com.br ${ }^{(5)}$ Fundação Agrária de Pesquisa Agropecuária, Praça Nova Pátria, s/no, Colônia Vitória Entre Rios, CEP $85139-400$ Guarapuava, PR. E-mail: juliano@agraria.com.br ${ }^{(6)}$ Nidera Sementes Ltda., Rua Saul Moreira Macedo, o 31, Cará-Cará, CEP $84045-980$ Ponta Grossa, PR. E-mail: GMatei@nidera.com.br
\end{abstract}

Resumo - O objetivo deste trabalho foi identificar as melhores épocas de semeadura e avaliar a adaptabilidade e a estabilidade de cultivares de trigo, em duas regiões tritícolas do Paraná. Avaliou-se a produtividade de grãos de sete cultivares, em Guarapuava, e de nove, em Palotina, em quatro épocas de semeadura, em 2006, 2007 e 2008. Utilizou-se o delineamento experimental de blocos ao acaso, com quatro repetições em Guarapuava, e três em Palotina. Foram utilizadas a metodologia REML/BLUP e a dos efeitos principais dos genótipos e da interação genótipo $\mathrm{x}$ ambiente (GGE biplot) para a avaliação da adaptabilidade e da estabilidade das cultivares, e o método AMMI para a identificação das melhores épocas de semeadura. Semeaduras em julho, em Guarapuava, e em abril, em Palotina, maximizam a produtividade de grãos. As cultivares Safira, em Guarapuava, e CD 113, em Palotina, são estáveis, amplamente adaptadas e apresentam alta produtividade de grãos.

Termos para indexação: Triticum aestivum, AMMI, GGE biplot, interação genótipo x ambiente, REML/BLUP.

\section{Adaptability and stability of wheat cultivars at different sowing dates in the state of Paraná, Brazil}

\begin{abstract}
The objective of this work was to identify the best sowing dates and to evaluate the adaptability and stability of wheat cultivars in two wheat growing regions of the state of Paraná, Brazil. Seven cultivars were evaluated at Guarapuava and nine at Palotina as to grain yield, at four sowing seasons, in 2006, 2007 and 2008. The experimental design was a randomized complete block design, with four and three replicates, for Guarapuava and Palotina, respectively. The methodologies REML/BLUP and genotype main effect and genotype $\mathrm{x}$ environment interaction (GGE biplot) were used for adaptability and stability analysis, and the AMMI model was used to identify the best sowing dates. Sowing in July, at Guarapuava, and in April, at Palotina, maximized grain yield. The cultivars Safira, at Guarapuava, and CD 113, at Palotina, are stable, highly adapted and show high grain yield.
\end{abstract}

Index terms: Triticum aestivum, AMMI, GGE biplot, genotype x environment interaction, REML/BLUP.

\section{Introdução}

O trigo (Triticum aestivum L.) é o cereal de maior importância econômica mundial, com mais de 600 milhões de toneladas produzidas anualmente. O Brasil contribui com cerca de seis milhões de toneladas, com destaque para a região Sul, responsável por 90\% da produção nacional (Companhia Nacional de Abastecimento, 2010), e para o estado do Paraná, o maior produtor do país.

A expressão do potencial de produtividade de grãos depende de fatores genéticos e ambientais, bem como da interação entre ambos, o que resulta em expressivas diferenças no desempenho das cultivares quando cultivadas em diferentes condições ambientais (Yan \& Holland, 2010). O termo ambiente (época de semeadura, ano e práticas culturais) pode ser definido como o resultado dos componentes biofísicos que influenciam o desenvolvimento e o crescimento das plantas.

O potencial de produtividade de grãos pode ser maximizado pela escolha adequada da época de semeadura, sem que se onere o custo de produção. Essa prática de manejo é considerada uma das mais importantes, pois são alteradas as relações hídricas

Pesq. agropec. bras., Brasília, v.46, n.11, p.1439-1447, nov. 2011 
e a temperatura e a radiação solar disponíveis à cultura ao longo de seu ciclo (Subedi et al., 2007). Além disso, essa prática permite a ocorrência das fenofases em condições favoráveis de clima, o que impacta positivamente a produtividade de grãos (Pires et al., 2009). A vernalização e o fotoperíodo interferem na duração de subperíodos importantes para a formação dos componentes da produtividade de grãos, e a resposta a estes fatores de ambiente é dependente da época de semeadura e do genótipo utilizado (Ribeiro et al., 2009).

O manejo da época de semeadura em trigo possibilita incremento na produtividade de grãos entre 10 e 80\% (Brunetta et al., 1997; Bassoi et al., 2005; Coventry et al., 2011). Na Índia, acreditavase que as primeiras épocas de semeadura eram as mais adequadas para maximizar o potencial de produtividade de grãos em trigo. Contudo, Coventry et al. (2011) demonstraram que algumas cultivares são mais responsivas a épocas de semeadura tardias. No Brasil, onde dezenas de cultivares são disponibilizadas para cultivo anualmente, é preciso buscar acerto mais adequado das épocas de semeadura do trigo, ao se considerar o ciclo e a adaptabilidade das cultivares às condições de clima e solo.

Para a escolha de cultivares mais adaptadas e estáveis a determinadas épocas de semeadura, é importante utilizar ferramentas estatísticas-biométricas que não subestimem ou superestimem o efeito do ambiente sobre a produtividade de grãos. Entre as metodologias recentes que tem explicado adequadamente os efeitos principais (genótipo e ambiente) e a sua interação, destacam-se: o modelo de efeitos principais aditivos e interação multiplicativa (AMMI) e a análise dos efeitos principais do genótipo e da interação genótipo $\mathrm{x}$ ambiente (GGE biplot). Essas metodologias, baseadas em gráfico biplot, são capazes de captar grande parte da variação do conjunto de dados referentes à importância relativa do genótipo e da interação genótipo x ambiente (Roozeboom et al., 2008). Outra metodologia, a REML/BLUP, permite a estimação dos componentes de variância por máxima verossimilhança restrita (REML) e a predição de valores genéticos pela melhor predição linear não viciada (BLUP) (Resende, 2002).
A aleatoriedade dos efeitos genotípicos é uma vantagem dessa metodologia (Resende et al., 2001), pois, ao admitir o efeito aleatório, não subestima a interação genótipo x ambiente (Yang, 2007).

O objetivo deste trabalho foi identificar as melhores épocas de semeadura e avaliar a adaptabilidade e a estabilidade de cultivares de trigo, em duas regiões tritícolas do Paraná.

\section{Material e Métodos}

O experimento foi conduzido em duas regiões tritícolas do Paraná: Guarapuava $\left(25^{\circ} 33^{\prime} \mathrm{S}\right.$ e $51^{\circ} 30^{\prime} \mathrm{W}$, a $1.095 \mathrm{~m}$ de altitude), com clima predominante do tipo $\mathrm{Cfb}$, subtropical úmido com verão temperado (Maack, 1968), conforme Köppen, e solo classificado como Latossolo Bruno alumínico típico (Santos et al., 2006); e Palotina $\left(24^{\circ} 17^{\prime} 02^{\prime} \mathrm{S}^{\prime}\right.$ e $53^{\circ} 50^{\prime} \mathrm{W}$, a $333 \mathrm{~m}$ de altitude), com clima predominante do tipo $\mathrm{Cfa}$, temperado úmido com verão quente, e solo classificado como Nitossolo Vermelho eutrófico. Guarapuava (VCU 1) destacase por apresentar elevado potencial produtivo, com ocorrência de geadas severas, enquanto Palotina é considerada uma das principais regiões produtivas (VCU 3) de trigo no estado, importante quanto ao volume e à qualidade do trigo produzido.

Utilizou-se o delineamento experimental de blocos ao acaso, com quatro repetições, em Guarapuava, e três em Palotina. Em Guarapuava, foram avaliadas as cultivares de diferentes ciclos de maturação: CD 105 e BRS Guamirim (precoce), CD 115, BRS Guabiju, BRS 179 e Safira (médio) e BRS Umbu (semitardio), com semeaduras realizadas em 1 e 15 de junho (E1 e E2) e em 1 e 15 de julho (E3 e E4). Em Palotina, foram avaliadas as cultivares: CD 104 e CD 112 (médio), CD 105, CD 108, CD 111, CD 113, CD 114 e IPR 85 (precoce) e Ônix (médio), com semeaduras realizadas em 5 e 20 de abril (E1 e E2) e em 5 e 20 de maio (E3 e E4). As cultivares foram selecionadas aleatoriamente e as mais representativas foram utilizadas em ambas as regiões.

As parcelas consistiram de seis linhas de $5 \mathrm{~m}$ de comprimento, com espaçamento de $0,17 \mathrm{~m}$ entre si, e a área útil das unidades experimentais foi de $5,1 \mathrm{~m}^{2}$. Em Guarapuava, a adubação de base foi de $300 \mathrm{~kg} \mathrm{ha}^{-1}$ da fórmula 8-30-20 (N-P-K), tendo-se 
utilizado $40 \mathrm{~kg} \mathrm{ha}^{-1}$ de $\mathrm{N}$, em cobertura, na forma de ureia, no início do perfilhamento. Em Palotina, foi realizada adubação de base na dose de $300 \mathrm{~kg} \mathrm{ha}^{-1}$ da fórmula 8-28-16 (N-P-K), com aplicação de $60 \mathrm{~kg} \mathrm{ha}^{-1}$ de $\mathrm{N}$ em cobertura, na forma de ureia, também no início do perfilhamento. Para a determinação da produtividade de grãos $\left(\mathrm{kg} \mathrm{ha}^{-1}\right)$, foi colhida a área útil da parcela e ajustada a massa dos grãos para $13 \%$ de umidade.

A adaptação das cultivares às épocas de semeadura foi avaliada com uso do modelo AMMI, que combina a análise de variância dos efeitos aditivos de genótipos e ambientes com a análise de componentes principais do efeito multiplicativo da interação genótipo x ambiente (Zobel et al., 1988), e do método GGE biplot, que considera o efeito do genótipo e da interação genótipo x ambiente (Yan et al., 2000). O modelo REML/BLUP (Resende, 2002) foi utilizado para identificar a capitalização ou a penalização em função das épocas de semeadura, na estimativa dos ganhos preditos.

O modelo AMMI selecionado para análise, em Guarapuava e Palotina, foi o AMMI3, a $1 \%$ de probabilidade, pelo teste de Gollob, cujos resíduos foram não significativos. Uma vez que a análise AMMI foi utilizada para a identificação das melhores épocas de semeadura, optou-se pela utilização da representação gráfica AMMI1, na qual o eixo $\mathrm{x}$ representa os efeitos principais de genótipos e ambientes, e o eixo y (IPCA1) é o primeiro eixo da interação.

O aplicativo computacional Genes (Cruz, 2001) foi utilizado para realizar a análise de variância conjunta, o aplicativo GGE biplot (Yan, 2001) para a análise GGE e AMMI, e o Selegen (Resende, 2002) para a análise REML/BLUP.

\section{Resultados e Discussão}

A análise de variância conjunta indicou que os efeitos de cultivares (C), anos (A) e épocas de semeadura (E) apresentaram variações significativas pelo teste F, a 1\% de probabilidade, em Guarapuava e em Palotina (Tabela 1). Os coeficientes de variação foram de 6,84 e 9,52\%, para Guarapuava e Palotina, respectivamente, o que afere boa precisão ao experimento. O maior valor do quadrado médio para anos, em Guarapuava, indica que, nessa localidade, houve maior influência da variação entre anos do que entre épocas de semeadura, provavelmente porque a região é propensa à ocorrência de geadas, fato observado na safra agrícola de 2006. Já em Palotina, observou-se maior importância da época de semeadura. Ao se considerar as interações significativas, as cultivares apresentaram alteração no posicionamento, de acordo com as diferentes épocas de semeadura.

A alta variância genotípica $\left(\sigma^{2} \mathrm{~g}\right)$, observada em Guarapuava, indica dificuldades na determinação da estabilidade produtiva para a região, pois nesse caso há tendência de superestimar a variância da interação genótipo x ambiente ( $\sigma^{2}$ int) (Tabela 2). Entretanto, os maiores valores da herdabilidade dos efeitos genotípicos totais $\left(\mathrm{h}^{2} \mathrm{~g}\right)$ e da herdabilidade da média das cultivares $\left(\mathrm{h}^{2} \mathrm{mg}\right)$ são indicativos de que a produtividade e o ganho de produtividade foram maiores em Guarapuava, em comparação à Palotina. Esses resultados $\left(\mathrm{h}^{2} \mathrm{~g}\right.$ e $\left.\mathrm{h}^{2} \mathrm{mg}\right)$ conferem maior acurácia (Acgen) na indicação de cultivares para cada época de semeadura em Guarapuava, em que o ganho de acurácia preditiva foi maior nos anos em que ocorreu menor instabilidade na produção, em concordância com Thomason \& Phillips (2006).

O coeficiente de determinação dos efeitos da interação genótipo $\mathrm{x}$ ambiente ( $\mathrm{c}^{2}$ int) foi alto apenas no primeiro ano $(0,56)$, em Guarapuava, em virtude da ocorrência de geada na primeira época de semeadura. Já em Palotina (região quente, moderadamente seca e baixa), essa estimativa, em todos os anos, foi considerada de alta magnitude, o que indica que o cultivo de trigo, em diferentes anos e épocas de

Tabela 1. Resumo da análise de variância para o caráter produtividade de grãos $\left(\mathrm{kg} \mathrm{ha}{ }^{-1}\right)$ de cultivares de trigo cultivadas em diferentes épocas de semeadura, em duas regiões tritícolas do Paraná.

\begin{tabular}{lccccc}
\hline Fonte de & \multicolumn{3}{c}{ Guarapuava } & & \multicolumn{2}{c}{ Palotina } \\
\cline { 2 - 3 } \cline { 5 - 6 } variação & GL & Quadrados médios & & GL & Quadrados médios \\
\hline Blocos & 36 & $400.792^{* *}$ & & 24 & $200.561^{* *}$ \\
Cultivares (C) & 6 & $2.960 .262^{* *}$ & & 8 & $2.063 .318^{* *}$ \\
Anos (A) & 2 & $300.594 .361^{* *}$ & & 2 & $6.748 .681^{* *}$ \\
Épocas (E) & 3 & $71.058 .521^{* *}$ & & 3 & $17.140 .380^{* *}$ \\
Cx A & 12 & $2.997 .361^{* *}$ & & 16 & $801.324^{* *}$ \\
C x E & 18 & $652.351^{*}$ & & 24 & $528.226^{* *}$ \\
A x E & 6 & $34.223 .213^{* *}$ & & 6 & $534.832^{* *}$ \\
C x A x E & 36 & $68.127^{* *}$ & & 48 & $280.591^{* *}$ \\
\hline CV (\%) & - & 6,84 & & - & 9,52 \\
\hline
\end{tabular}

** e *Significativo pelo teste F, a 1 e $5 \%$ de probabilidade, respectivamente. 
semeadura, está sujeito à maior interação genótipo $\mathrm{x}$ ambiente. Quando a correlação genotípica entre o desempenho nas diferentes épocas de semeadura (rgloc) é alta, como observado em Guarapuava, principalmente nas safras agrícolas de $2008(0,86)$ e $2009(0,76)$, ocorre menor interação genótipo $\mathrm{x}$ ambiente entre as cultivares e as épocas de semeadura.

Ao se considerar o modelo AMMI1, a interação genótipo $\mathrm{x}$ ambiente foi do tipo imprevisível em ambas as regiões (Figura 1), pois não houve agrupamento entre épocas de semeaduras semelhantes, mas entre épocas do mesmo ano. Isso ocorreu em razão de o fator ano, que nem sempre é repetível, ter apresentado maior efeito sobre a produtividade de grãos, em comparação às épocas de semeadura. Em Guarapuava, o modelo AMMI1 indicou que a terceira e a quarta épocas de semeadura (E3 e E4, respectivamente) proporcionaram maior média produtiva durante os três anos de avaliação (Figura 2). No entanto, em Palotina, o cultivo em épocas antecipadas (E1 e E2) possibilitou maior

Tabela 2. Estimativas de parâmetros genéticos para as cultivares de trigo avaliadas em três anos e quatro épocas de semeadura, obtidas com uso da metodologia REML.

\begin{tabular}{|c|c|c|c|c|c|c|}
\hline \multirow[t]{2}{*}{ Parâmetro(1) } & \multicolumn{3}{|c|}{ Guarapuava } & \multicolumn{3}{|c|}{ Palotina } \\
\hline & 2006 & 2007 & 2008 & 2006 & 2007 & 2008 \\
\hline$\overline{\sigma^{2} g}$ & 214.736 & 186.054 & 41.744 & 184.320 & 411 & 46.357 \\
\hline$\sigma^{2}$ int & 338.148 & 30.079 & 13.504 & 128.414 & 73.145 & 85.037 \\
\hline$h^{2} g$ & $0,36 \pm 0,16$ & $0,58 \pm 0,20$ & $0,28 \pm 0,142$ & $0,53 \pm 0,2$ & $0,002 \pm 0,013$ & $0,25 \pm 0,14$ \\
\hline $\mathrm{h}^{2} \mathrm{mg}$ & 0,71 & 0,92 & 0,82 & 0,83 & 0,015 & 0,64 \\
\hline Acgen & 0,84 & 0,96 & 0,90 & 0,91 & 0,12 & 0,8 \\
\hline$c^{2}$ int & 0,56 & 0,09 & 0,09 & 0,37 & 0,4 & 0,46 \\
\hline rgloc & 0,39 & 0,86 & 0,76 & 0,59 & 0,005 & 0,35 \\
\hline $\mathrm{C} \sigma^{2}$ gi $(\%)$ & 13,7 & 7,8 & 3 & 15 & 0,65 & 8 \\
\hline $\mathrm{C} \sigma^{2} \mathrm{e}(\%)$ & 6,7 & 5,9 & 4,6 & 6,7 & 10 & 9 \\
\hline Produtividade média $\left(\mathrm{kg} \mathrm{ha}^{-1}\right)$ & 3.373 & 5.497 & 6.607 & 2.840 & 3.100 & 2.604 \\
\hline
\end{tabular}

${ }^{(1)} \sigma^{2} \mathrm{~g}$, variância genotípica; $\sigma^{2}$ int, variância da interação genótipo x ambiente; $h^{2} \mathrm{~g}$, herdabilidade dos efeitos genotípicos totais; $\mathrm{h}^{2} \mathrm{mg}$, herdabilidade da média da cultivar; Acgen, acurácia da seleção de cultivares; $c^{2}$ int, coeficiente de determinação dos efeitos da interação genótipo x ambiente; rgloc, correlação genotípica entre o desempenho nas diferentes épocas de semeadura; $\mathrm{C}^{2}$ gi, coeficiente de variação genotípica; $C \sigma^{2}$ e, coeficiente de variação residual.
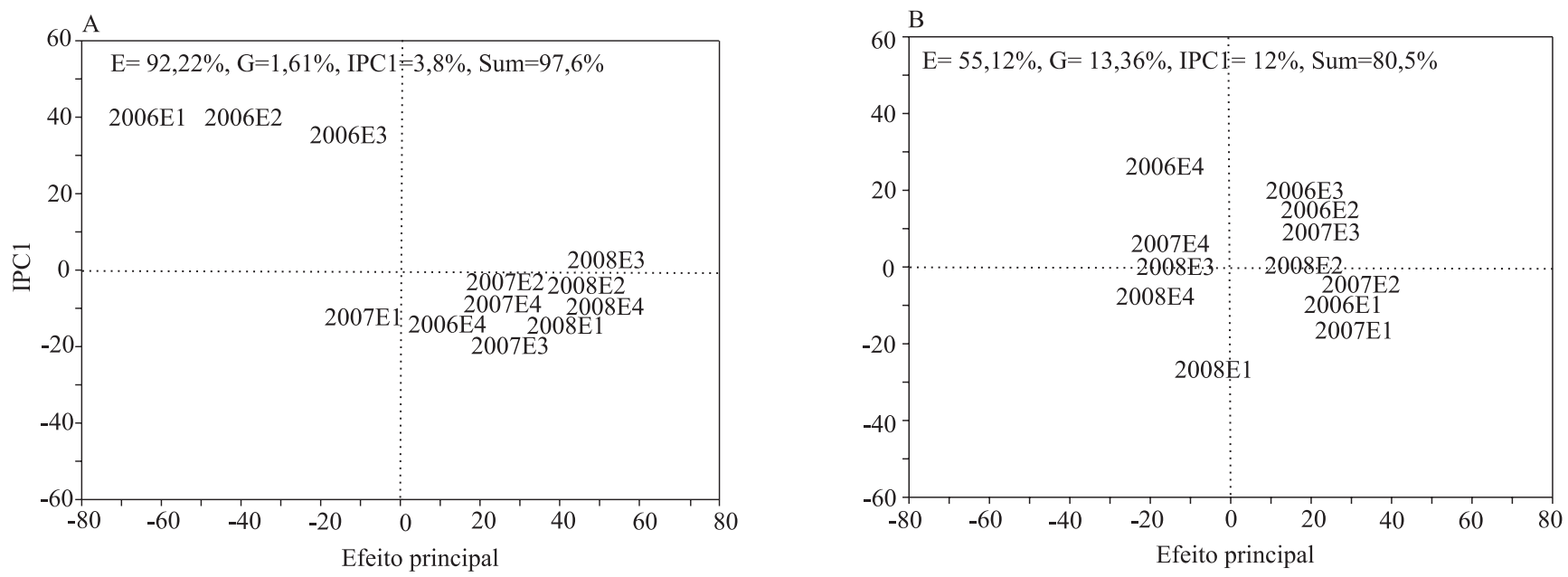

Figura 1. Plotagem dos escores dos componentes principais, quanto à interação genótipo $\mathrm{x}$ ambiente, segundo análise conjunta do modelo AMMI1 (2006, 2007 e 2008), para o caráter produtividade de grãos ( $\left.\mathrm{kg} \mathrm{ha}^{-1}\right)$ de cultivares de trigo, avaliadas em quatro épocas de semeadura (E1, E2, E3 e E4), em Guarapuava (A) e em Palotina (B). 
média de produtividade de grãos durante os três anos de experimento.

No gráfico biplot, uma cultivar é adaptada a determinado ambiente quando está situada no mesmo quadrante do ambiente ou quando apresenta ângulo inferior a $90^{\circ}$ com este ambiente (Yan \& Kang, 2003). A cultivar BRS Umbu apresentou adaptação específica a E1, em 2006 (Figura 3), mas correlação negativa perfeita com E1, no último ano de cultivo. Com exceção de BRS Umbu, que apresenta ciclo tardio, as demais cultivares semeadas em E1 sofreram danos por geada. A cultivar Safira apresentou adaptabilidade a E1 (2008), E2 (2006, 2007 e 2008), E3 (2006 e 2007) e E4 (2007 e 2008); portanto, ela deve ser considerada amplamente adaptada e menos sujeita a variações na produtividade, em comparação à BRS Umbu. Em Palotina, as cultivares CD 105 (2006), IPR 85 (2007), CD 104 (2007) e CD 112 (2008) apresentaram maior contribuição à interação genótipo x ambiente, o que indica maiores respostas ao efeito das épocas de semeadura avaliadas (Figura 3). As cultivares CD 105 (2006), Ônix (2007 e 2008) e CD 104 (2007 e 2008) apresentaram-se adaptadas à primeira época de semeadura (E1), enquanto as cultivares IPR 85 (2006), CD 112 e CD 113 (2007 e 2008) apresentaram melhor desempenho produtivo em E2. Foram poucas as cultivares adaptadas às ultimas épocas de semeadura (E3 e E4), pois, nessas condições, fatores de ambiente limitantes, como deficiência hídrica e alta temperatura, prejudicaram o seu desempenho.

Com base nesses resultados, a recomendação de épocas de semeadura a partir de julho, em Guarapuava, e em abril, em Palotina (Figura 3), está de acordo com Gonçalves et al. (1998). Estes autores observaram que o risco de geadas aumenta de forma proporcional em altitude e latitude maiores, nas quais as épocas de semeadura do sul do estado, em comparação ao norte, devem ser tardias para minimizar o risco de danos por geadas no espigamento. Contudo, a semeadura tardia pode submeter a cultura à ocorrência de deficiência hídrica no espigamento, com risco maior no norte do estado (Cunha et al., 2001; Fietz et al., 2005). A ocorrência de altas temperaturas em semeaduras tardias, em Palotina, é extremamente prejudicial à produtividade de grãos da cultura do trigo, por aumentar o abortamento floral e reduzir o período de enchimento
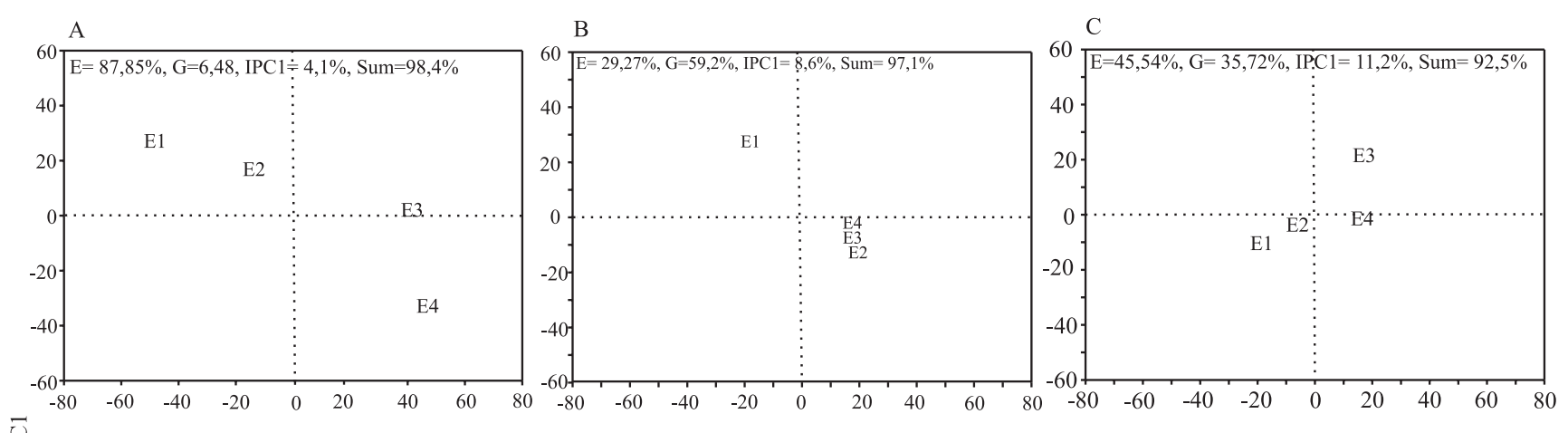

ఏ
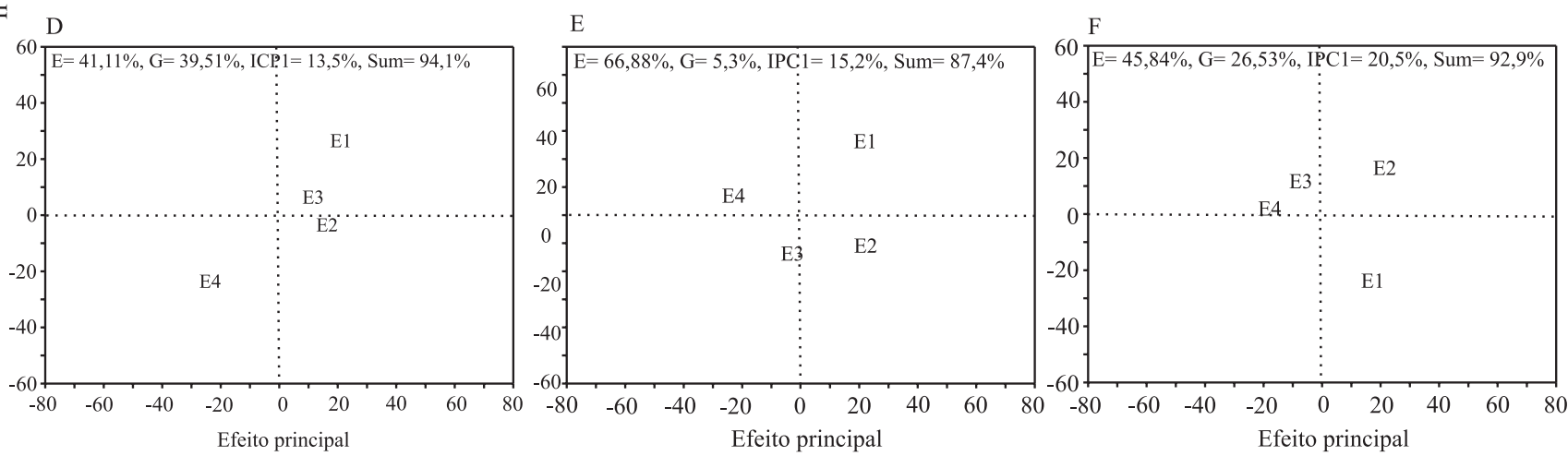

Figura 2. Plotagem dos escores dos componentes principais, quanto à indicação de épocas de semeadura, segundo o modelo AMMI1, em Guarapuava, em 2006 (A), 2007 (B) e 2008 (C), e em Palotina, em 2006 (D), 2007 (E) e 2008 (F), para o caráter produtividade de grãos $\left(\mathrm{kg} \mathrm{ha}^{-1}\right)$ de cultivares de trigo, avaliadas em quatro épocas de semeadura (E1, E2, E3 e E4). 
de grãos, o que provoca perdas na produtividade final (García del Moral et al., 2003). Além disso, semeaduras tardias, em Palotina, estão sujeitas à deficiência hídrica no espigamento (Gonçalves et al., 1998).

Em relação ao desempenho relativo das cultivares em Guarapuava e Palotina, em todos os anos, as cultivares foram classificadas ao longo de dois eixos (Figura 4). O eixo com seta única indica a maior média produtiva, e o com duas setas a estabilidade das cultivares. Devese ressaltar que, quanto maior a projeção, menor é a estabilidade das cultivares (Yan \& Kang, 2003).

Em Guarapuava, as cultivares BRS Umbu (2006), CD 105 (2007) e BRS 179 (2008) foram as mais produtivas, enquanto a cultivar Safira apresentou maior estabilidade e produtividade nos três anos de experimento (Figura 4). Em Palotina, as cultivares CD 108 (2006 e 2008) e CD 114 (2007) apresentaram maior média produtiva, e a cultivar CD 113 foi a mais estável e produtiva durante os três anos. A cultivar ideal é definida com base em dois critérios: alta produtividade e estabilidade (Yan \& Kang, 2003). Assim, as cultivares Safira, em Guarapuava, e
CD 113, em Palotina, são consideradas como ideais, pois apresentaram elevada produtividade de grãos aliada a alta estabilidade.

Os ganhos das cultivares em cada época de semeadura foram estimados por meio da metodologia BLUP. Em Guarapuava (Tabela 3), em 2006, o cultivo na primeira época foi viável apenas com a cultivar BRS Umbu, que apresentou maior média produtiva predita (2.259 $\mathrm{kg} \mathrm{ha}^{-1}$ ). Em Palotina (Tabela 4), as cultivares CD 108 e CD 113, com maior média produtiva pela metodologia GGE biplot, apresentaram maior ganho predito em épocas específicas, principalmente em E3 e E4.

As análises gráficas dos métodos AMMI e GGE permitiram a apresentação e a interpretação dos dados de forma simples e de fácil entendimento. Essas análises, associadas aos valores genotípicos e aos ganhos genéticos preditos, estimados na escala do caráter avaliado, com uso da metodologia REML/ BLUP, permitiram clara indicação das melhores épocas de semeadura e adaptação específica ou geral das cultivares às épocas de semeadura avaliadas.
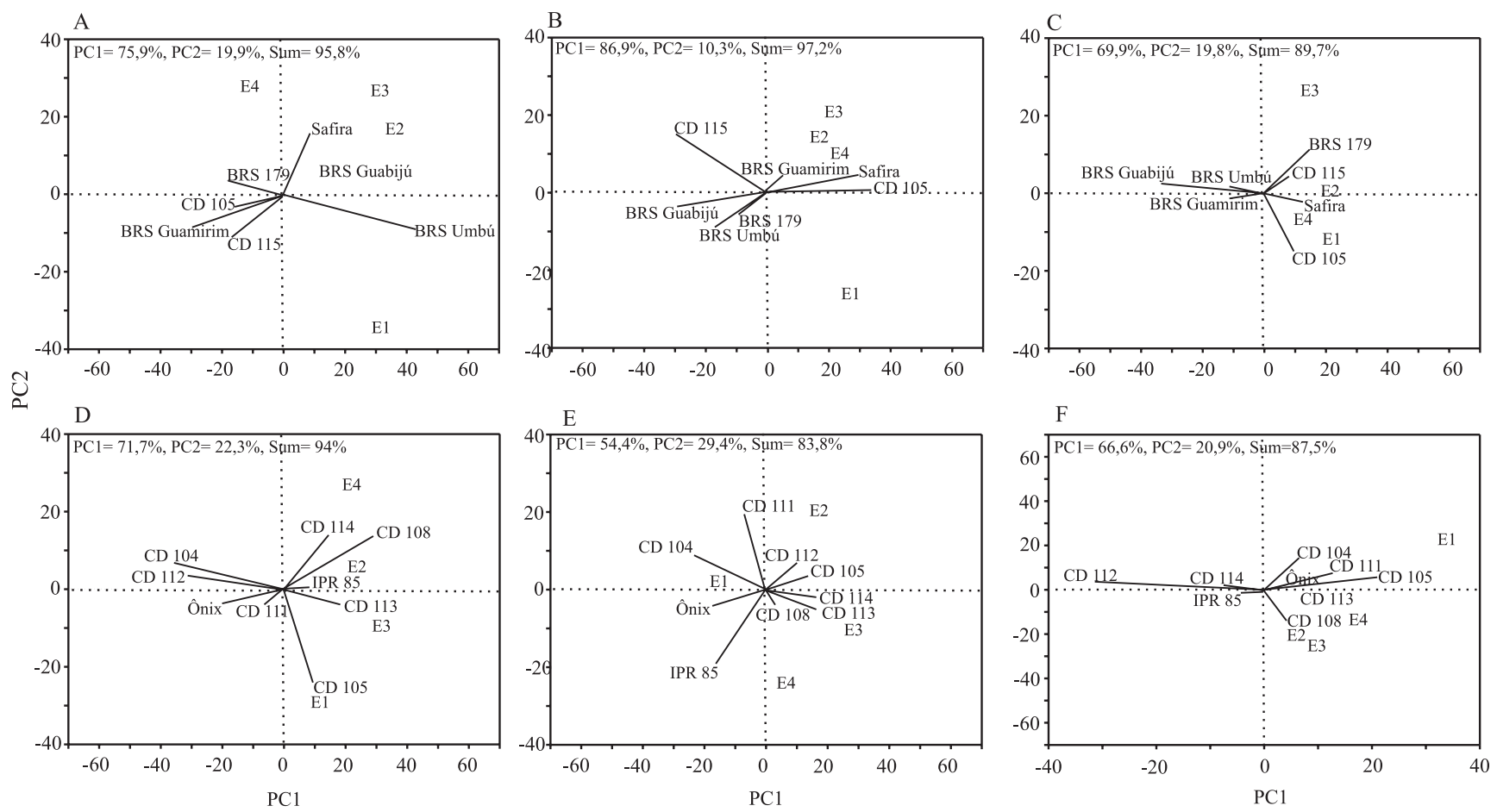

Figura 3. Plotagem dos escores dos componentes principais, quanto à indicação de épocas de semeadura, segundo o modelo GGE biplot, em Guarapuava, em 2006 (A), 2007 (B) e 2008 (C), e em Palotina, em 2006 (D), 2007 (E) e 2008 (F), para o caráter produtividade de grãos $\left(\mathrm{kg} \mathrm{ha}^{-1}\right)$ de cultivares de trigo, avaliadas em quatro épocas de semeadura (E1, E2, E3 e E4). 

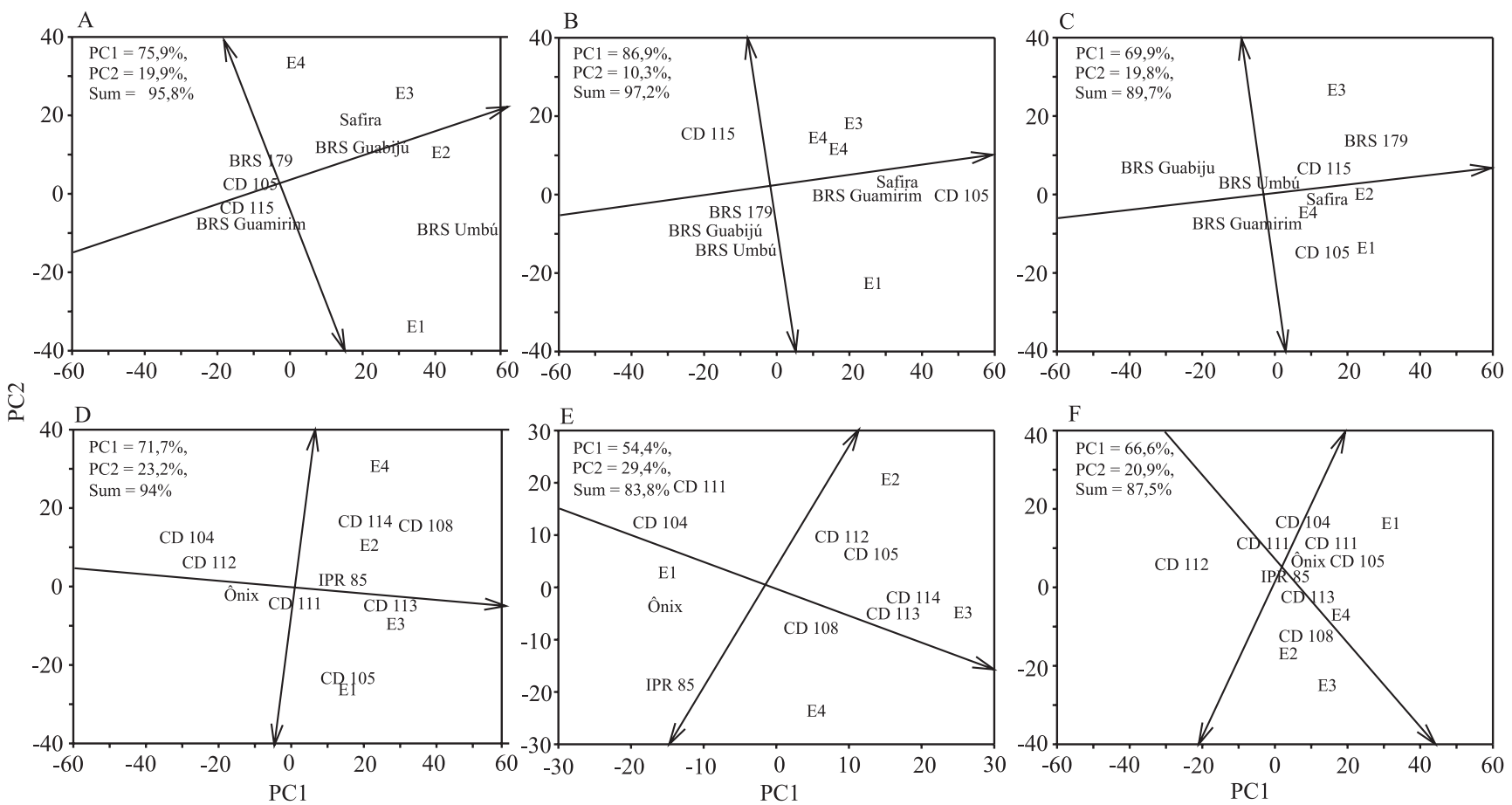

Figura 4. Plotagem dos escores dos componentes principais, quanto à indicação da média e à estabilidade produtiva, segundo o modelo GGE biplot, em Guarapuava, em 2006 (A), 2007 (B) e 2008 (C), e em Palotina, em 2006 (D), 2007 (E) e 2008 (F), para o caráter produtividade de grãos $\left(\mathrm{kg} \mathrm{ha}^{-1}\right)$ de cultivares de trigo, avaliadas em quatro épocas de semeadura (E1, E2, E3 e E4).

Tabela 3. Valores genotípicos ( $\mathrm{g}+\mathrm{ge})$, ganhos genéticos preditos (Ganho) e nova média da produtividade de grãos $\left(\mathrm{kg} \mathrm{ha}^{-1}\right)$ de cultivares de trigo, estimados por meio da metodologia BLUP, em três anos e quatro épocas de semeadura, em Guarapuava.

\begin{tabular}{|c|c|c|c|c|c|c|c|c|c|c|c|c|c|c|c|}
\hline \multirow[t]{2}{*}{ Cultivar } & \multicolumn{3}{|c|}{$1^{o}$ de junho } & \multicolumn{3}{|c|}{15 de junho } & \multicolumn{3}{|c|}{$1^{o}$ de julho } & \multicolumn{3}{|c|}{15 de julho } & \multicolumn{3}{|c|}{ Todas as épocas } \\
\hline & $\mathrm{g}+\mathrm{ge}$ & Ganho & Nova média & $\mathrm{g}+\mathrm{ge}$ & Ganho & Nova média & $\mathrm{g}+\mathrm{ge}$ & Ganho & Nova média & $\mathrm{g}+\mathrm{ge}$ & Ganho & Nova média & $\mathrm{g}+\mathrm{ge}$ & Ganho & Nova média \\
\hline & \multicolumn{15}{|c|}{ Ano 2006} \\
\hline BRS Umbu & 1.886 & 1.886 & 2.259 & 1.391 & 1.391 & 4.585 & 810 & 819 & 5.498 & -547 & 0 & 5.246 & 635 & 635 & 4.008 \\
\hline BRS 179 & -319 & 259 & 632 & -694 & 166 & 3.360 & -117 & 528 & 5.207 & 526 & 526 & 5.772 & -108 & 257 & 3.630 \\
\hline BRS Guamirim & -342 & 138 & 512 & -997 & 0 & 3.194 & -723 & 0 & 4.679 & & 192 & 5.438 & -416 & 0 & 3.373 \\
\hline BRS Guabiju & -296 & 451 & 825 & 433 & 846 & 4.040 & 590 & 743 & 5.422 & 294 & 429 & 5.675 & 183 & 379 & 3.752 \\
\hline CD 105 & -346 & 58 & 431 & -304 & 558 & 3.752 & -712 & 120 & 4.800 & -70 & 304 & 5.550 & -257 & 154 & 3.527 \\
\hline CD 115 & -347 & 0 & 373 & -542 & 338 & 3.532 & -677 & 287 & 4.966 & -412 & 91 & 5.337 & -355 & 69 & 3.442 \\
\hline \multirow[t]{2}{*}{ Safira } & -236 & 825 & 1.199 & 714 & 1.052 & 4.246 & 828 & 828 & 5.507 & 467 & 496 & 5.742 & 318 & 476 & 3.850 \\
\hline & \multicolumn{15}{|c|}{ Ano 2007} \\
\hline BRS Umbu & -143 & 221 & 5.242 & -329 & 0 & 5.649 & -336 & 70 & 5.720 & -289 & 176 & 5.844 & -263 & 155 & 5.652 \\
\hline BRS 179 & -11 & 311 & 5.333 & -194 & 213 & 5.861 & -218 & 264 & 5.914 & -115 & 292 & 5.961 & -129 & 260 & 5.757 \\
\hline BRS Guamirim & 6 & 419 & 5.440 & -37 & 348 & 5.997 & 83 & 425 & 6.075 & 95 & 428 & 6.096 & 35 & 389 & 5.886 \\
\hline BRS Guabiju & -328 & 129 & 5.150 & -279 & 55 & 5.703 & -417 & 0 & 5.650 & -480 & 0 & 5.668 & -362 & 69 & 5.566 \\
\hline CD 105 & 729 & 729 & 5.751 & 577 & 577 & 6.226 & 704 & 704 & 6.354 & 582 & 595 & 6.263 & 623 & 623 & 6.120 \\
\hline CD 115 & -775 & 0 & 5.021 & -279 & 55 & 5.703 & -303 & 151 & 5.801 & -400 & 80 & 5.748 & -414 & 0 & 5.496 \\
\hline \multirow[t]{2}{*}{$\underline{\text { Safira }}$} & 522 & 626 & 5.647 & 504 & 541 & 6.190 & 487 & 595 & 6.245 & 607 & 607 & 6.275 & 509 & 566 & 6.063 \\
\hline & \multicolumn{15}{|c|}{ Ano 2008} \\
\hline BRS Umbu & -173 & 69 & 6.321 & -44 & 107 & 6.638 & -92 & 52 & 6.914 & -119 & 53 & 6.837 & -99 & 57 & 6.664 \\
\hline BRS 179 & 209 & 218 & 6.470 & 209 & 209 & 6.740 & 338 & 338 & 7.200 & 197 & 197 & 6.981 & 220 & 220 & 6.828 \\
\hline BRS Guamirim & -62 & 117 & 6.369 & -113 & 70 & 6.601 & -84 & 81 & 6.943 & -10 & 87 & 6.871 & -62 & 88 & 6.695 \\
\hline BRS Guabiju & -411 & 0 & 6.253 & -421 & 0 & 6.531 & -314 & 0 & 6.862 & -318 & 0 & 6.784 & -339 & 0 & 6.607 \\
\hline CD 105 & 167 & 201 & 6.453 & 116 & 161 & 6.693 & -66 & 123 & 6.985 & 102 & 134 & 6.918 & 74 & 125 & 6.733 \\
\hline CD 115 & 45 & 162 & 6.414 & 159 & 184 & 6.715 & 93 & 186 & 7.048 & 46 & 87 & 6.871 & 79 & 142 & 6.750 \\
\hline Safira & 226 & 226 & 6.479 & 94 & 144 & 6.676 & 127 & 232 & 7.094 & 102 & 149 & 6.934 & 127 & 174 & 6.781 \\
\hline
\end{tabular}


Tabela 4. Valores genotípicos (g+ge), ganhos genéticos preditos (Ganho) e nova média da produtividade de grãos $\left(\mathrm{kg} \mathrm{ha}^{-1}\right)$ de cultivares de trigo, estimados por meio da metodologia BLUP, em três anos e quatro épocas de semeadura, em Palotina.

\begin{tabular}{|c|c|c|c|c|c|c|c|c|c|c|c|c|c|c|c|}
\hline \multirow[t]{2}{*}{ Cultivar } & \multicolumn{3}{|c|}{5 de abril } & \multicolumn{3}{|c|}{20 de abril } & \multicolumn{3}{|c|}{5 de maio } & \multicolumn{3}{|c|}{20 de maio } & \multicolumn{3}{|c|}{ Todas as épocas } \\
\hline & $\mathrm{g}+\mathrm{ge}$ & Ganho & Nova média & $\mathrm{g}+\mathrm{ge}$ & Ganho & Nova média & $\mathrm{g}+\mathrm{ge}$ & Ganho & Nova média & $\mathrm{g}+\mathrm{ge}$ & Ganho & Nova média & $\mathrm{g}+\mathrm{ge}$ & Ganho & Nova média \\
\hline & \multicolumn{15}{|c|}{ Ano 2006} \\
\hline CD 104 & 1.010 & 1.010 & 4.279 & -759 & 0 & 3.051 & -1.035 & 0 & 2.943 & -509 & 68 & 2.164 & -617 & 0 & 2.840 \\
\hline CD 105 & -593 & 0 & 3.269 & 75 & 397 & 3.449 & 419 & 566 & 3.509 & -335 & 253 & 2.349 & 249 & 337 & 3.177 \\
\hline CD 108 & 60 & 330 & 3.599 & 701 & 701 & 3.753 & 663 & 713 & 3.656 & 1.040 & 1.040 & 3.136 & 525 & 525 & 3.365 \\
\hline CD 111 & 73 & 420 & 3.690 & 19 & 322 & 3.373 & 5 & 387 & 3.330 & -323 & 370 & 2.466 & -48 & 235 & 3.075 \\
\hline CD 112 & -545 & 74 & 3.343 & -607 & 95 & 3.146 & -793 & 129 & 3.073 & -465 & 150 & 2.246 & -513 & 77 & 2.917 \\
\hline CD 113 & 179 & 594 & 3.864 & 326 & 505 & 3.556 & 762 & 762 & 3.705 & 127 & 544 & 2.639 & 297 & 411 & 3.251 \\
\hline CD 114 & -30 & 215 & 3.484 & 487 & 594 & 3.646 & 53 & 464 & 3.407 & 798 & 919 & 3.015 & 279 & 367 & 3.207 \\
\hline IPR 85 & 0 & 264 & 3.533 & -126 & 195 & 3.247 & 421 & 616 & 3.559 & 209 & 682 & 2.778 & 107 & 291 & 3.131 \\
\hline \multirow[t]{2}{*}{ Ônix } & -153 & 163 & 3.432 & -116 & 249 & 3.300 & -496 & 261 & 3.204 & -543 & 0 & 2.096 & -278 & 161 & 3.001 \\
\hline & \multicolumn{15}{|c|}{ Ano 2007} \\
\hline CD 104 & 141 & 155 & 3.608 & -173 & 58 & 3.547 & -408 & 0 & 3.065 & -259 & 41 & 2.434 & -4 & 0 & 3.100 \\
\hline CD 105 & -19 & 102 & 3.554 & 135 & 194 & 3.683 & 315 & 315 & 3.380 & -144 & 84 & 2.477 & 2 & 2 & 3.102 \\
\hline CD 108 & 131 & 149 & 3.601 & -31 & 128 & 3.617 & 198 & 246 & 3.311 & 20 & 151 & 2.544 & 2 & 2 & 3.102 \\
\hline CD 111 & 33 & 126 & 3.578 & 179 & 213 & 3.703 & -198 & 108 & 3.173 & -326 & 0 & 2.393 & -2 & 0 & 3.100 \\
\hline CD 112 & -70 & 77 & 3.529 & 262 & 262 & 3.751 & 71 & 199 & 3.264 & -24 & 122 & 2.515 & 1 & 2 & 3.102 \\
\hline CD 113 & -379 & 0 & 3.452 & 23 & 160 & 3.649 & 185 & 231 & 3.296 & 108 & 183 & 2.577 & 0 & 1 & 3.101 \\
\hline CD 114 & -163 & 47 & 3.499 & 199 & 230 & 3.720 & 226 & 271 & 3.336 & 222 & 222 & 2.615 & 3 & 3 & 3.103 \\
\hline IPR 85 & 160 & 163 & 3.615 & -463 & 0 & 3.489 & -43 & 159 & 3.224 & 205 & 214 & 2.607 & -1 & 1 & 3.101 \\
\hline \multirow[t]{2}{*}{ Ônix } & 166 & 166 & 3.618 & -130 & 91 & 3.580 & -347 & 51 & 3.116 & 198 & 209 & 2.602 & -1 & 1 & 3.101 \\
\hline & \multicolumn{15}{|c|}{ Ano 2008} \\
\hline CD 104 & 336 & 449 & 3.264 & -40 & 225 & 3.223 & -343 & 54 & 2.530 & 109 & 255 & 2.381 & 11 & 83 & 2.688 \\
\hline CD 105 & 597 & 597 & 3.413 & -65 & 152 & 3.151 & -31 & 141 & 2.617 & 272 & 327 & 2.453 & 132 & 158 & 2.762 \\
\hline CD 108 & -95 & 239 & 3.054 & 498 & 498 & 3.496 & 413 & 413 & 2.889 & 256 & 303 & 2.430 & 184 & 158 & 2.788 \\
\hline CD 111 & 414 & 506 & 3.321 & -79 & 106 & 3.104 & -2 & 220 & 2.696 & 7 & 205 & 2.332 & 58 & 114 & 2.718 \\
\hline CD 112 & -1.099 & 0 & 2.816 & -224 & 0 & 2.998 & -436 & 0 & 2.476 & -622 & 0 & 2.126 & -408 & 0 & 2.604 \\
\hline CD 113 & -49 & 306 & 3.121 & -80 & 75 & 3.073 & 213 & 295 & 2.771 & 382 & 382 & 2.509 & 80 & 132 & 2.736 \\
\hline CD 114 & -230 & 137 & 2.953 & -126 & 28 & 3.026 & -5 & 175 & 2.651 & -215 & 78 & 2.204 & -99 & 51 & 2.655 \\
\hline IPR 85 & -104 & 190 & 3.005 & 216 & 357 & 3.355 & -67 & 111 & 2.587 & -10 & 169 & 2.296 & 6 & 72 & 2.677 \\
\hline Ônix & 231 & 394 & 3.210 & -99 & 50 & 3.049 & 259 & 336 & 2.812 & -180 & 120 & 2.246 & 36 & 98 & 2.702 \\
\hline
\end{tabular}

\section{Conclusões}

1. Semeaduras realizadas em julho, em Guarapuava, e abril, em Palotina, proporcionam alta produtividade de grãos em trigo.

2. Semeaduras em maio, em Palotina, devem ser realizadas com cultivares de ciclo precoce, como a CD 108.

3. Em Guarapuava, semeaduras em junho apresentam elevada produtividade com a adoção de cultivares com ciclo médio e tardio, como a BRS Umbu.

4. As cultivares Safira, em Guarapuava, e CD 113, em Palotina, apresentam alta estabilidade, ampla adaptabilidade e alta produtividade de grãos quando cultivadas em diferentes épocas de semeadura.

\section{Referências}

BASSOI, M.C.; BRUNETTA, D.; DOTTO, S.R.; SCHEEREN, P.L.; CAETANO, V. da R.; TAVARES, L.C.V.; MIRANDA, L.C. Características e desempenho agronômico no Paraná da cultivar de trigo BRS 220. Pesquisa Agropecuária Brasileira, v.40, p.193-196, 2005.

BRUNETTA, D.; DOTTO, S.R.; FRANCO, F. de A.; BASSOI, M.C. Cultivares de trigo do Paraná: rendimento, características agronômicas e qualidade industrial. Londrina: Embrapa-CNPSo, 1997. 48p. (Embrapa-CNPSo. Circular técnica, 18).

COMPANHIA NACIONAL DE ABASTECIMENTO. Acompanhamento da safra brasileira. Brasília: Conab, 2010. 45p.

COVENTRY, D.R.; GUPTA, R.K.; YADAV, A.; POSWAL, R.S.; CHHOKAR, R.S.; SHARMA, R.K.; YADAV, V.K.; GILL, S.C.; KUMAR, A.; MEHTA, A.; KLEEMANN, S.G.L.; BONAMANO, A.; CUMMINS, J.A. Wheat quality and productivity as affected by varieties and sowing time in Haryana, India. Field Crops Research, v.123, p.214-225, 2011. 
CRUZ, C.D. Programa genes: aplicativo computacional em genética e estatística. Viçosa: UFV, 2001. 648p.

CUNHA, G.R. da; HAAS, J.C.; MALUF, J.R.T.; CARAMORI, P.H.; ASSAD, E.D.; BRAGA, H.J.; ZULLO JÚNIOR, J.; LAZZAROTTO, C.; GONÇALVES, S.;WREGE, M.;BRUNETTA, D.; DOTTO, S.R.; PINTO, H.S.; BRUNINI, O.; THOMÉ, V.M.R.; ZAMPIERI, S.L.; PASINATO, A.; PIMENTEL, M.B.M.; PANDOLFO, C. Zoneamento agrícola e época de semeadura para o trigo no Brasil. Revista Brasileira de Agrometeorologia, v.9, p.400-414, 2001.

FIETZ, C.R.; SOUSA, P.G.; URCHER, M.A. Análise da época de semeadura para trigo na região de Dourados, MS. Revista Brasileira de Agrometeorologia, v.13, p.59-63, 2005.

GARCÍA DEL MORAL, L.F.; RHARRABTI, Y.; VILLEGAS, D.; ROYO, C. Evaluation of grain yield and its components in durum wheat under Mediterranean conditions: an ontogenic approach. Agronomy Journal, v.95, p.266-274, 2003.

GONÇALVES, S.L.; CARAMORI, P.H.; WREGE, M.S.; BRUNETTA, D.; DOTTO, S. Regionalização para épocas de semeadura de trigo no Estado do Paraná. Revista Brasileira de Agrometeorologia, v.6, p.239-248, 1998.

MAACK, R. Geografia física do Estado do Paraná. Curitiba: Banco de Desenvolvimento do Paraná, 1968. 350p.

PIRES, J.L.F.; SANTOS, H.P. dos; SCHEEREN, P.L.; MIRANDA, M.Z. de; DE MORI, C.; CASTRO, R.L. de; CAIERÃO, E.; PILAU, J. Avaliação de cultivares de trigo em diferentes níveis de manejo na região do Planalto do Rio Grande do Sul. Passo Fundo: Embrapa Trigo, 2009. 23p. (Embrapa Trigo. Boletim de pesquisa e desenvolvimento online, 74).

RESENDE, M.D.V. de. Genética biométrica e estatística no melhoramento de plantas perenes. Brasília: Embrapa Informação Tecnológica; Colombo: Embrapa Florestas, 2002. 975p.

RESENDE, M.D.V. de; FURLANI-JÚNIOR, E.; MORAES, M.L.T. de; FAZUOLI, L.C. Estimativas de parâmetros genéticos e predição de valores genotípicos no melhoramento do cafeeiro pelo procedimento REML/BLUP. Bragantia, v.60, p.185-193, 2001.
RIBEIRO, T.L.P.; CUNHA, G.R. da; PIRES, J.L.F.; PASINATO, A. Respostas fenológicas de cultivares brasileiras de trigo à vernalização e ao fotoperíodo. Pesquisa Agropecuária Brasileira, v.44, p.1383-1390, 2009.

ROOZEBOOM, K.L.; SCHAPAUGH, W.T.; TUINSTRA, M.R.; VANDERLIP, R.L.; MILLIKEN, G.A. Testing wheat in variable environments: genotype, environment, interaction effects, and grouping test locations. Crop Science, v.48, p.317-330, 2008.

SANTOS, H.G. dos; JACOMINE, P.K.T.; ANJOS, L.H.C. dos; OLIVEIRA, V.A. de; OLIVEIRA, J.B. de; COELHO, M.R.; LUMBRERAS, J.F.; CUNHA, T.J.F. (Ed.). Sistema brasileiro de classificação de solos. 2.ed. Rio de Janeiro: Embrapa Solos, 2006. $306 \mathrm{p}$.

SUBEDI, K.D.; MA, B.-L.; XUE, A.G. Planting date and nitrogen effects on grain yield and protein content of spring wheat. Crop Science, v.47, p.36-47, 2007.

THOMASON, W.E.; PHILLIPS, S.B. Methods to evaluate wheat cultivar testing environments and improve cultivar selection protocols. Field Crops Research, v.99, p.87-95, 2006.

YAN, W. GGEbiplot - a windows application for graphical analysis of multienvironment trial data and other types of two-way data. Agronomy Journal, v.93, p.1111-1118, 2001.

YAN, W.; HOLLAND, J.B. A heritability-adjusted GGE biplot for test environment evaluation. Euphytica, v.171, p.355-369, 2010 .

YAN, W.; HUNT, L.A.; SHENG, Q.L.; SZLAVNICS, Z. Cultivar evaluation and mega-environment investigation based on the GGE biplot. Crop Science, v.40, p.597-605, 2000.

YAN, W.; KANG, M.S. GGE biplot analysis: a graphical tool for breeders, geneticists, and agronomists. Boca Raton: CRC, 2003. 288p.

YANG, R.C. Mixed-model analysis of crossover genotypeenvironment interactions. Crop Science, v.47, p.1051-1062, 2007.

ZOBEL, R.W.; WRIGHT, M.J.; GAUCH, H.G. Statistical analysis of a yield trial. Agronomy Journal, v.80, p.388-393, 1988.

Recebido em 18 de março de 2011 e aprovado em 24 de outubro de 2011 